LETTER TO JMG

\title{
DFNA49, a novel locus for autosomal dominant non- syndromic hearing loss, maps proximal to DFNA7/DFNM1 region on chromosome 1q21-q23
}

\author{
M A Moreno-Pelayo*, S Modamio-Hoybjør*, A Mencía, I del Castillo, S Chardenoux, \\ M Fernández-Burriel, M Lathrop, C Petit, F Moreno
}

J Med Genet 2003;40:832-836

\begin{abstract}
A pproximately 1 in 1000 children is born with a serious permanent hearing impairment (pre-lingual deafness), and it is estimated that more than half of these cases in developed countries are due to genetic factors. ${ }^{1-3}$ The prevalence of hearing loss increases dramatically with age; it is estimated that approximately $5 \%$ of people under 45 years of age have a significant loss of hearing, increasing to approximately $50 \%$ by 80 years of age. ${ }^{1}$ Age related late onset hearing loss (presbycusis) is a heterogeneous trait with many suspected causes.. ${ }^{4}$ Genetic or environmental factors such as diabetes, mitochondrial mutations, or environmental noise exposure may contribute to the trait. In addition, hearing loss beginning at late childhood, youth, or later, clearly segregates as a monogenic autosomal dominant Mendelian trait in many families. The hearing loss phenotype in these families is usually non-syndromic - that is, the hearing loss is not associated with other anomalies, and it accounts for up to $20 \%$ of the cases of non-syndromic sensorineural inherited deafness. This type of hearing loss is usually progressive, affecting a particular range of frequencies in each case. ${ }^{5}$ To date, 36 loci for autosomal dominant non-syndromic sensorineural hearing loss (ADNSSHL) have been mapped, and 17 deafness genes from these loci have been identified. ${ }^{6}$ These genes encode a wide variety of proteins; some have known function but for most, the underlying mechanisms leading to hearing impairment are uncertain. Given the few described mouse models for progressive hearing loss, ${ }^{7}$ our current understanding of post-lingual and progressive deafness relies on the identification of genes through human mapping studies. In this work we describe the mapping of a novel DFNA locus on chromosome 1q21-q23 segregating in a Spanish family with post-lingual and progressive hearing loss.
\end{abstract}

\section{PATIENTS AND METHODS}

Family data

We ascertained a four generation family (S277) segregating ADNSSHL, through the Hospital Universitario Materno Infantil. The pedigree consists of 31 members, fourteen of them affected (fig 1). Informed consent was obtained from all study participants and from parents of subjects younger than 18 years. Clinical history interview and physical examination of members of this family ruled out environmental factors as the cause of the hearing loss. Peripheral blood samples were collected from 27 family members and DNA extraction was performed following standard methods. Tympanometry indicated proper functioning of the middle ear, and acoustic reflex thresholds showed the presence of recruitment in affected subjects. Clinical and instrumental evaluation did not reveal any evidence of syndromic features. Pure tone audiometry was performed to test for air conduction $(125-8000 \mathrm{~Hz})$ and bone conduction $(250-4000 \mathrm{~Hz})$.

\section{Key points}

- Autosomal dominant inheritance accounts for about $20 \%$ of the cases of hereditary non-syndromic sensorineural hearing loss (NSSHL) - that is, hearing loss not associated with other clinical features. So far, 36 loci have been mapped in familial cases that segregate autosomal dominant NSSHL (DFNA), and 17 genes have been identified.

- Here we report the location of a novel autosomal dominant deafness locus on 1q21-q23, DFNA49, found by studying a large Spanish family with nonsyndromic, progressive mid-frequency hearing loss of post-lingual onset. A maximum lod score of 6.02 at $\theta=0$ was obtained for markers D1S3784 and D1S3785. Analysis of recombinant haplotypes placed the deafness locus within a $4 \mathrm{cM}$ region defined by markers GDB: 190880 and D1S3786.

- This genetic interval is proximal to and does not overlap with the previously identified loci, DFNA7 and DFNM1, on 1q21-q23.

- Screening of candidate genes within the DFNA49 interval (KCNJ9, KCNJ10, ATP1A2 and CASQ1) did not reveal the mutation causing this deafness.

Where possible, results from previous audiological tests were collected.

\section{Genotyping and linkage analysis}

A wide genome scan was performed with 394 microsatellite markers distributed with an average spacing of $10 \mathrm{cM}$ (ABI Prism Linkage Mapping Set 2; Applied Biosystems, Foster City, CA, USA). Markers for the exclusion of all known DFNA loci and for fine mapping of the critical interval were taken from the Généthon human linkage map ${ }^{8}$ and from the Marshfield chromosome 1 map (http://research.marshfieldclinic.org/genetics). Additional short tandem repeats (STRs) in the DFNA49 region were identified by inspection of publicly available sequence data (NCBI: http://www. ncbi.nlm.nih.gov). Flanking primers were designed for polymerase chain reaction (PCR) amplification of these

Abbreviations: ADNSSHL, autosomal dominant non-syndromic sensorineural hearing loss; NSSHL, non-syndromic sensorineural hearing loss; PCR, polymerase chain reaction; STRs, short tandem repeats 
STRs. The amplicons were confirmed to be polymorphic microsatellite markers and deposited into the GDB database (http://www.gdb.org), being assigned the following D numbers: D1S3780 (GDB: 11511382), D1S3783 (GDB: 11511388), D1S3784 (GDB: 11511390), D1S3785 (GDB: 11511392), and D1S3786 (GDB: 11511394). The order of markers used in this work was established by integrating genetic and physical maps (NCBI).

Fluorescently labelled alleles were analysed in an ABI Prism 310 automated DNA sequencer (Applied Biosystems). Linkage analysis was performed using the Linkage 5.1 software package. ${ }^{9}$ Two point lod scores between the deafness locus and each marker were calculated under a fully penetrant autosomal dominant mode of inheritance, setting the disease allele frequency to 0.00001 and considering marker allele frequencies to be equal to each other.

\section{DNA sequencing analysis}

Four candidate genes, KCNJ9 (MIM600932), KCNJ10 (MIM602208), ATPIA2 (MIM182340) and CASQ1 (MIM114250) in the DFNA49 interval were screened by heteroduplex analysis and direct sequencing of PCR products generated from genomic DNA of affected subjects. Primers were designed to amplify each exon and adjacent intron-exon boundaries. PCR was performed by standard procedures as previously described ${ }^{10}$ Heteroduplex analysis was carried out in mutation detection enhancement gels (BioWhittaker, Rockland, ME, USA) according to the manufacturer's protocol. Sequences of PCR products were analysed in an automated DNA sequencer (ABI Prism 310; Applied Biosystems).

\section{RESULTS AND DISCUSSION}

\section{Clinical features}

Affected subjects of the family present a symmetrical, bilateral, and progressive nonsyndromic sensorineural hearing loss. The hearing loss appears in the first decade of life in affected members. The earliest clinical evidence of hearing loss in the family was obtained from individual III:12 at the age of 8 years. Initially, the hearing loss in this family is moderate for low and mid frequencies and mild for high frequencies (4000-8000 Hz), so the affected members show in this stage a gently upsloping audiometric profile. Later, it progresses to moderate in the $125-250 \mathrm{~Hz}$ and $4000-8000 \mathrm{~Hz}$ ranges and to severe in the $500-2000 \mathrm{~Hz}$ range (U shaped audiometric profile) in the fourth decade. Linear regression analysis, based on all available audiograms from affected subjects, showed a $0.7 \mathrm{~dB}$ /year age linked progression of the hearing loss at all frequencies. Affected subjects of the family did not exhibit either tinnitus or clinical features suggestive of vestibular dysfunction.

\section{Linkage analysis}

Linkage to previously published loci responsible for autosomal dominant deafness (DFNA) was investigated in a core pedigree of 26 persons (subject IV:3 is 20 months old, clearly below the age of deafness onset, and therefore he was not included in the linkage analysis) obtaining negative results. A wide genome search was then performed to map the deafness locus, using a set of 394 microsatellite markers with an average spacing of $10 \mathrm{cM}$. Interestingly, the two point lod scores obtained for markers D1S498 (3.01 at theta $=0)$ and D1S484 (3.72 at theta $=0.05)$ on chromosome $1 \mathrm{q} 21-\mathrm{q} 23$

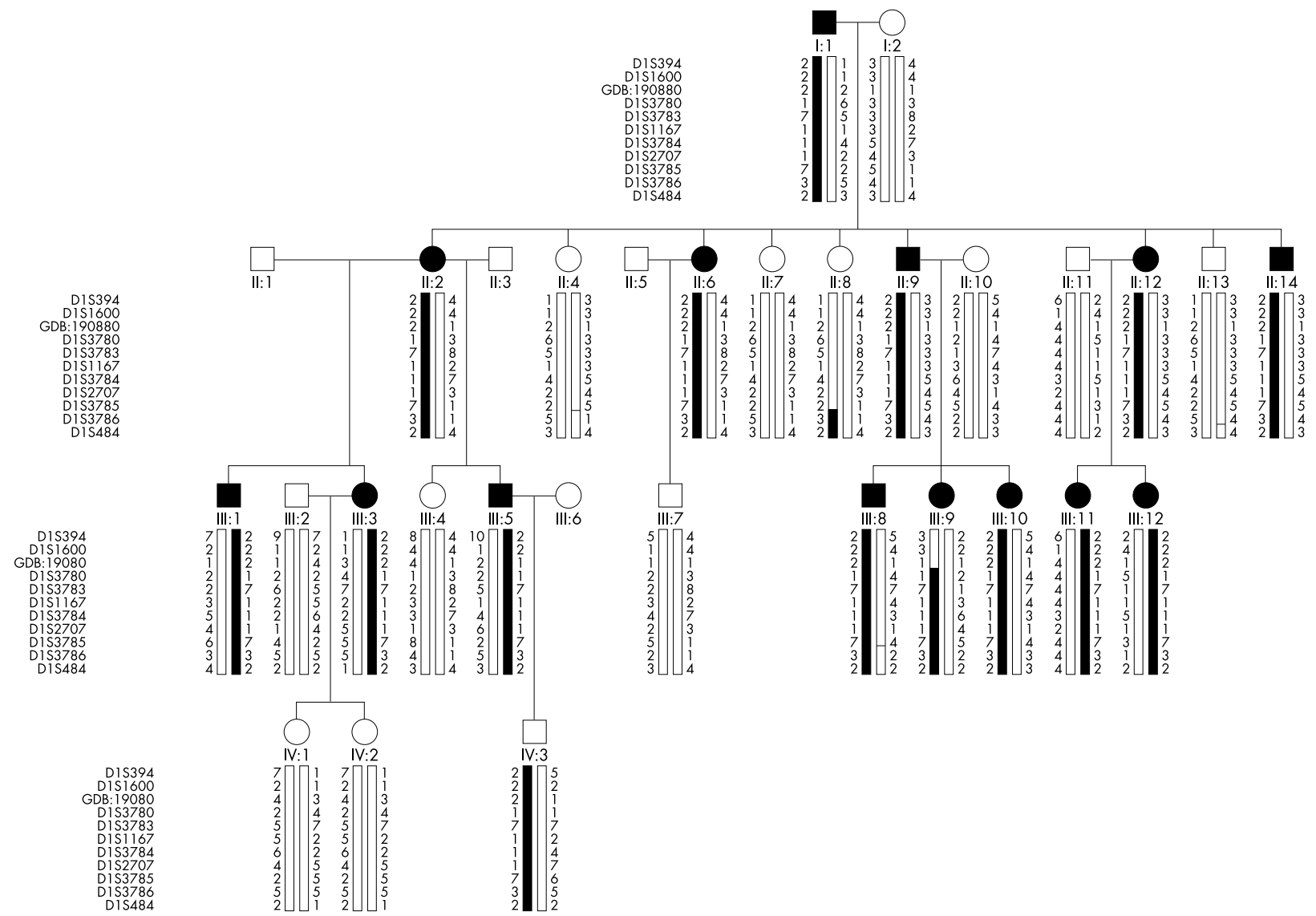

Figure 1 Pedigree and haplotype analysis of the Spanish family S277. Black symbols represent affected subjects. Haplotypes are represented by bars, with the haplotype associated with hearing loss in black. At the time of the study affected subjects III: 12, III: 11, III: 10, III: 9 and III:8 were 8, $14,15,17$ and 18 years old respectively. 


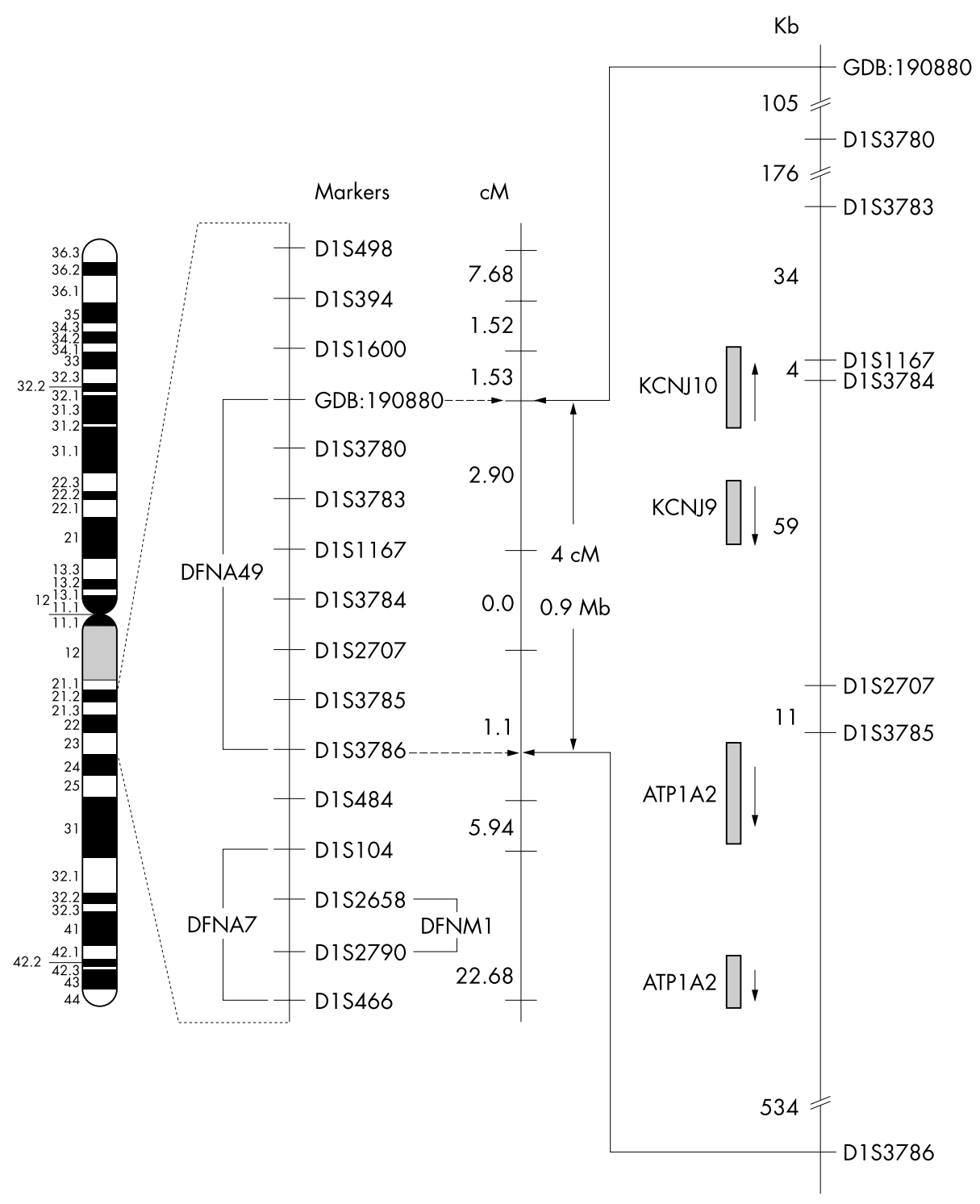

Figure 2 Physical and genetic maps of the chromosome 1q21-q23 region showing the localisation of DFNA49 and DFNA7/DFNM1 critical intervals. cM, centimorgan; kb, kilobase. KCNJ9 (OMIM \#600932); KCNJ10 (OMIM \#602208); ATPIA2 (OMIM \#182340) and CASQ1 (OMIM $\# 1$ 14250). For clarity, the genetic and physical distances are not represented to scale.

were suggestive of linkage to this region (fig 2). We then tested additional markers spanning this region, and evidence of linkage to markers DiS3780, D1S3783, D1S1167, and D1S2707 was found, with maximum two point lod scores of 6.02 at theta $=0$ for markers D1S3784 and DiS3785 (table 1 ). Extensive alterations of the disease gene frequency or the allele frequencies of microsatellite markers did not change the conclusions of the analysis. The inspection of recombinant haplotypes in subjects III:9 and II:8 placed the hearing loss locus between the proximal marker GDB: 190880 and the distal one DIS3786, which define a critical interval of about $4 \mathrm{cM}$ for the novel locus, DFNA49 (fig 1 and 2). All the patients in the family share the same disease haplotype, which is also carried by the 20 month old child IV:3. Periodic audiometric examination of this subject will be performed to precisely determine when the hearing impairment begins in this family.

Another dominant locus for hearing loss (DFNA7) was mapped to a $22 \mathrm{cM}$ region on 1q21-q23 between D1S104 and D1S466 in a Norwegian family ${ }^{11}$ (fig 2). The DFNA7 interval has been reported to include the DFNMI locus, a dominant modifier that suppresses the DFNB26 phenotype. ${ }^{12}$ The
DFNA7/DFNMl region had previously been excluded for linkage in our family. As shown in fig 2, a genetic distance of 6 cM separates this interval and the one defined for DFNA49. It should also be noted that the audiometric response associated with DFNA7 and DFNA49 in the reported families is clearly different. DFNA7 patients show a sharply sloping audiogram affecting the high frequencies, instead of the $U$ shaped audiometric pattern found in the DFNA49 affected subjects.

\section{Candidate gene analysis}

No genes for syndromic deafness have been mapped to DFNA49 critical interval. This interval spans $0.9 \mathrm{Mb}$ and includes 23 known genes and several predicted or poorly characterised genes according to the annotation in the NCBI database. Of these, we selected ATPIA2, CASQ1, KCNJ10 and KCNJ9 for screening of mutations (fig 2).

ATPIA2 consists of 23 exons $^{13}$ and encodes the NaK-ATPase $\alpha 2$ subunit, which is responsible for the catalytic activity of the enzyme. In mouse cochlea, the $\alpha 2$ isoform is expressed in the spiral structures: ligament, limbus, and ganglion ${ }^{14}$, where it is believed to play an important role in the development 
Table 1 Two point lod scores between 1q microsatellite markers and DFNA49

\begin{tabular}{llllllllll}
\hline \multicolumn{7}{c}{ Recombination fractions $(\boldsymbol{\theta})$} \\
\cline { 2 - 8 } Marker & $\mathbf{0 . 0 0}$ & $\mathbf{0 . 0 1}$ & $\mathbf{0 . 0 5}$ & $\mathbf{0 . 1 0}$ & $\mathbf{0 . 2 0}$ & $\mathbf{0 . 3 0}$ & $\mathbf{0 . 4 0}$ & $\mathbf{Z}_{\max }$ & $\boldsymbol{\theta}_{\text {max }}$ \\
\hline D1S394 & $-\infty$ & 3.93 & 4.27 & 4.11 & 3.38 & 2.40 & 1.20 & 4.27 & 0.05 \\
D1S1600 & $-\infty$ & 3.34 & 3.72 & 3.59 & 2.98 & 2.11 & 1.04 & 3.72 & 0.05 \\
GDB:190880 & $-\infty$ & 0.97 & 1.51 & 1.60 & 1.44 & 1.09 & 0.62 & 1.60 & 0.10 \\
D1S3780 & 5.72 & 5.63 & 5.27 & 4.80 & 3.78 & 2.62 & 1.29 & 5.72 & 0.00 \\
D1S3783 & 5.42 & 5.34 & 5.00 & 4.55 & 3.58 & 2.48 & 1.21 & 5.42 & 0.00 \\
D1S1167 & 3.31 & 3.26 & 3.04 & 2.76 & 2.16 & 1.49 & 0.76 & 3.31 & 0.00 \\
D1S3784 & 6.02 & 5.93 & 5.55 & 5.06 & 3.99 & 2.77 & 1.37 & 6.02 & 0.00 \\
D1S2707 & 5.42 & 5.34 & 5.00 & 4.55 & 3.58 & 2.48 & 1.21 & 5.42 & 0.00 \\
D1S3785 & 6.02 & 5.93 & 5.55 & 5.06 & 3.99 & 2.77 & 1.37 & 6.02 & 0.00 \\
D1S3786 & $-\infty$ & 3.93 & 4.27 & 4.11 & 3.38 & 2.40 & 1.21 & 4.27 & 0.05 \\
D1S484 & $-\infty$ & 3.34 & 3.72 & 3.59 & 2.98 & 2.11 & 1.05 & 3.72 & 0.05 \\
\hline
\end{tabular}

and maintenance of the fluid and electrolyte balance. CASQ1 has 11 exons ${ }^{15}$ and codes for calsequestrin, a calcium binding protein found in the cytoplasm of outer hair cells where it is thought to store and release calcium from membrane bound intracellular storage sites. ${ }^{16}$ Calcium is believed to play a major signalling role in outer hair cells by controlling metabolism, cytoskeletal integrity, cell shape, and cell excitability. KCNJ10 consists of two exons ${ }^{17}$ and encodes an inwardly rectifying $\mathrm{K}+$ channel subunit that is strongly expressed in the cochlear stria vascularis, where it is crucially involved in the generation of the endocochlear potential, 1819 and in the satellite cells that surround the neurones and axons of the cochlear and vestibular ganglia. ${ }^{20}$ Knockout mice for KCNJ10 present a profound deafness and severe structural degeneration of the cochlea. ${ }^{21}{ }^{22}$ KCNJ9 has three exons ${ }^{23}$ and codes for a $\mathrm{K}+$ channel with structural and functional similarity to $\mathrm{KCNJ10},{ }^{24}$ although its expression has not been reported in the inner ear so far.

The exons and flanking regions of the four genes were investigated by heteroduplex and DNA sequencing in two affected subjects (I:1 and II:2). These analysis only revealed the non-pathogenic polymorphisms, $1097 \mathrm{~T} \rightarrow \mathrm{C}$ in exon 3 of KCNJ9 (NCBI SNP cluster id: rs3001040) and the IVS1$84 \mathrm{~T} \rightarrow \mathrm{C}$ intronic change in KCNJ10, which was present in several control individuals with normal hearing. This last polymorphism allowed us to verify the presence in affected subjects of the two intact copies of KCNJIO exon 2, which include the entire coding region, so excluding the deletion of, or insertions in, this exon as the cause of deafness (data not shown).

Reports of more families with hearing deficit linked to DFNA49 may enable a further refinement of the critical interval facilitating the identification of the responsible gene. We are now searching for novel candidate genes at the DFNA49 interval.

\section{ACKNOWLEDGEMENTS}

We are grateful to the Spanish family who made this research possible. This work was supported by grants from the Comision Interministerial de Ciencia y Tecnología CICYT-SAF 99-0025, the Ministerio de Ciencia y Tecnología SAF 2002-03966, and the European Comunity QLG2-CT-1999-0098. S Modamio-Høybjør, and A Mencía are Fellows, respectively, of the Ministerio de Ciencia y Tecnología and Fondo de Investigaciones Sanitarias.

\section{Authors' affiliations}

M Angel Moreno-Pelayo, S Modamio-Høybjør, A Mencía, I del Castillo, F Moreno, Unidad de Genética Molecular, Hospital Ramón y Cajal, Madrid, Spain

S Chardenoux, C Petit, Unité de Génétique des Déficits Sensoriels, CNRS URA 1968, Institut Pasteur, Paris, France
M Fernández-Burriel, Laboratorio de Genética Molecular, Hospital Universitario Materno Infantil, Las Palmas de Gran Canaria, Spain M Lathrop, Centre National de Génotypage, Evry, France

*The first two authors contributed equally to this work and the order of authorship is arbitrary.

Correspondence to: Dr F Moreno, Unidad de Genética Molecular, Hospital Ramón y Cajal, Carretera de Colmenar Km 9, 28034, Madrid, Spain; fmoreno.hrc@salud.madrid.org

\section{REFERENCES}

1 Morton NE. Genetic epidemiology of hearing impairment. Ann N Y Acad Sci $1991 ; 630: 16-31$

2 Reardon W. Genetic deafness. J Med Genet 1992;29:521-6.

3 Marazita ML, Ploughman LM, Rawlings B, Remington E, Arnos KS, Nance WE. Genetic epidemiological studies of early-onset deafness in the U.S. school-age population. Am J Med Genet 1993;46:486-91.

4 Schuknecht HF, Gacek MR. Cochlear pathology in presbycusis. Otol Rhinol Laryngol 1993;102:1-16.

5 Bom SJ, Kunst HP, Huygen PL, Cremers FP, Cremers CW. Non-syndromal autosomal dominant hearing impairment: ongoing phenotypical characterization of genotypes. Br J Audiol 1999;33:335-48.

6 Van Camp G, Smith RJH. Hereditary Hearing Loss 2003. http://dnalabwww.via.ac.be/dnalab/hhh.

7 Vreugde S, Erven A, Kros CJ, Marcotti W, Fuchs H, Kurima K, Wilcox ER, Friedman TB, Griffith AJ, Balling R, Hrabe De Angelis M, Avraham KB, Steel KP. Beethoven, a mouse model for dominant, progressive hearing loss DFNA36. Nat Genet 2002;30:257-8.

8 Dib C, Faure S, Fizames C, Samson D, Drouot N, Vignal A, Millasseau P, Marc S, Hazan J, Seboun E, Lathrop M, Gyapay G, Morissette J, Weissenbach J. A comprehensive genetic map of the human genome based on 5,264 microsatellites. Nature 1996:380:152-4.

9 Lathrop GM, Lalouel JM, Julier C, Ott J. Multilocus linkage analysis in humans: detection of linkage and estimation of recombination. Am J Hum Genet 1985;37:482-98

10 Del Castillo I, Villamar M, Moreno-Pelayo MA, del Castillo FJ, Alvarez A, Telleria D, Menéndez I, Moreno F. A deletion involving the connexin 30 gene in nonsyndromic hearing impairment. N Engl J Med 2002;346:243-9.

11 Fagerheim T, Nilssen, Raeymaekers P, Brox V, Moum T, Elverland HH, Teig E, Omland $\mathrm{HH}$, Fostad GK, Tranebjaerg L. Identification of a new locus for autosomal dominant non-syndromic hearing impairment (DFNA7) in a large Norwegian family. Hum Mol Genet 1996;5:1187-91.

12 Riazuddin S, Castelein CM, Ahmed ZM, Lalwani AK, Mastroianni MA, Naz S, Smith TN, Liburd NA, Friedman TB, Griffith AJ, Riazuddin S, Wilcox ER Dominant modifier DFNM1 suppresses recessive deafness DFNB26. Nat Genet 2000;26:431-4.

13 Shull MM, Pugh DG, Lingrel JB. Characterization of the human Na,K-ATPase alpha 2 gene and identification of intragenic restriction fragment length polymorphisms. J Biol Chem 1989;264:17532-43.

14 Erichsen S, Zuo J, Curtis L, Rarey K, Hultcrantz M. Na,K-ATPase $\alpha$ - and $\beta$ isoforms in the developing cochlea of the mouse. Hear Res 1996;100:143-9.

15 Fujii J, Willard HF, MacLennan DH. Characterization and localization to human chromosome 1 of human fast-twitch skeletal muscle calsequestrin gene. Somat Cell Mol Genet 1990:16:185-9.

16 Slepecky NB, Ulfendahl M. Evidence for calcium-binding proteins and calcium-dependent regulatory proteins in sensory cells of the organ of Corti. Hear Res 1993;70:73-84.

17 Shuck ME, Piser TM, Bock JH, Slightom JL, Lee KS, Bienkowski MJ. Cloning and characterization of two $\mathrm{K}+$ inward rectifier (Kir) 1.1 potassium channel homologs from human kidney (Kir1.2 and Kir1.3). J Biol Chem 1997;272:586-93.

18 Hibino H, Horio $Y$, Inanobe A, Doi K, Ito M, Yamada M, Gotow T, Uchiyama Y, Kawamura M, Kubo T, Kurachi Y. An ATP-dependent inwardly 
rectifying potassium channel, KAB-2 (Kir4.1), in cochlear stria vascularis of inner ear: its specific subcellular localization and correlation with the formation of endocochlear potential. J Neurosci 1997; 17:4711-21.

19 Ando M, Takeuchi S. Immunological identification of an inward rectifier K+ channel (Kir4.1) in the intermediate cell (melanocyte) of the cochlear stria vascularis of gerbils and rats. Cell Tissue Res 1999;298:179-83.

20 Hibino H, Horio Y, Fujita A, Inanobe A, Doi K, Gotow T, Uchiyama Y Kubo T, Kurachi Y. Expression of an inwardly rectifying $\mathrm{K}(+)$ channel, Kir4.1, in satellite cells of rat cochlear ganglia. Am J Physiol 1999;277:C638-44.
21 Marcus DC, Wu T, Wangemann P, Kofuji P. KCNJ10 (Kir4.1) potassium channel knockout abolishes endocochlear potential. Am J Cell Physiol 2002;282: C403-7.

22 Rozengurt N, Lopez I, Chiu CS, Kofuji P, Lester HA, Neusch C. Time course of inner ear degeneration and deafness in mice lacking the Kir4.1 potassium channel subunit. Hearing Res 2003;177:71-80.

23 Vaughn J, Wolford JK, Prochazka M, Permana PA. Genomic structure and expression of human KCNJ9 (Kir3.3/GIRK3). Biochem Biophys Res Commun 2000;274:302-9.

24 Lehmann-Horn F, Jurkat-Rott K. Voltage-gated ion channel and hereditary disease. Physiol Rev 1999;79:1317-72.

\section{$\mathrm{ECHO}$}

\section{Susceptibility to Crohn's disease may lurk in enzyme mutation}

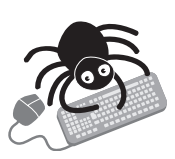

Please visit the Journal of Medical Genetics website [www. imedgenet.com] for a link to the full text of this article.
A preliminary study of genetic polymorphisms affecting transforming enzymes in the gut has singled out for the first time microsomal epoxide hydrolase as a likely candididate for susceptibility to Crohn's disease (CD).

Homozygous Tyr 113 substitution for His 113 in exon 3 of the microsomal epoxide hydrolase $(E P X H)$ gene was the only one of seven variants in a series of genes coding for detoxifying enzymes with a significantly higher frequency in patients with CD than controls (47\% v 21\%, respectively). Tyr/Tyr genotype was also more common within the patient group than in the control group (allele frequency $0.67 v 0.61$, respectively), and the odds of having the Tyr 113 allele were almost three times higher. This variant and another, in exon 4 of the same gene, were not associated with disease site, disease onset, fistulas, or history of bowel resection.

The variants were identified by PCR-RFLP (restriction fragment length polymorphism). They included those in cytochrome P-450 1AlC (CYPIAl 3' flanking region, CYPIAl exon 7); glutathione S-transferases mu-1, pi-1, and theta-1 (GSTM1, GSTPI, GSTT1); and epoxide hydrolases $(E P X H)$ in exons 3 and 4. Screening was performed on 151 consecutive outpatients at a hospital clinic in the Netherlands and age and sex matched healthy controls; all were Caucasian.

Reactive oxygen species and their toxic metabolites have been implicated in inflammation of the gut in CD. Detoxifying enzymes, such as glutathione S-transferases and epoxide hydrolases, may also have a role, so polymorphisms affecting their activity may affect risk of developing CD.

A Gut 2003;52:547-551. 